\title{
Reduced Degree of Phase Coexistence in KNN-Based Ceramics by Competing Additives
}

Xiang Lv1,2, Jiagang Wu1*, and Xi-xiang Zhang2*

1 Department of Materials Science, Sichuan University, Chengdu 610064, P. R. China

2 Division of Physical Science and Engineering, King Abdullah University of Science and Technology (KAUST), Thuwal 239955, Kingdom of Saudi Arabia

Correspondence e-mail: wujiagang0208@163.com and msewujg@scu.edu.cn (J. W) and xixiang.zhang@kaust.edu.sa (X-x. Z)

\begin{abstract}
This work reveals the role of $\mathrm{Bi}_{3}+$ in the controlling ability of ( $\left.\mathrm{Bi} 0.5 \mathrm{Ag}_{0.5}\right) \mathrm{ZrO}_{3}$ to the phase structure of potassium sodium niobate based ceramics by introducing Ba2+. The substitution on $\left(\mathrm{Bi}_{0.5} \mathrm{Ag}_{0.5}\right)_{2}+$ with $\mathrm{Ba}_{2}+$ results in the reduced degree of phase coexistence, accompanying the phase transition from coexisting orthorhombic-tetragonal $(\mathrm{O}-\mathrm{T})$ phases to an orthorhombic $(\mathrm{O})$ phase, which is demonstrated by the systematic phase structure analysis and variations of electrical properties. The analysis reveals that the high electronegativity of $\mathrm{Bi} 3+$ results in the increased covalent bond character and then increases the stabilization of the $\mathrm{T}$ phase, leading to a decrease in orthorhombic-tetragonal phase transition temperature (ТО-т). Therefore, this work not only compares the controlling ability of Ba2+ and (Bi0.5Ag0.5)2+ to TO-T but also reveals which and how elements cause the decreased To-T, promoting the understanding of the effect of additives on the phase structure.
\end{abstract}

Keywords: Lead-free ceramics; KNN; Phase structure; Electronegativity; Physical mechanism 


\section{Introduction}

Driven by the increasing demand for sustainable development, environmentally friendly lead-free piezoceramics are developed to hopefully replace the lead-based counterparts [1-5]. Particularly, the milestone reported by Saito et al. accelerated the development of potassium sodium niobate $\{(\mathrm{K}$, $\mathrm{Na}) \mathrm{NbO}_{3}, \mathrm{KNN}$ \} based ceramics due to the promising piezoelectricity and temperature stability [6]. The pronounced piezoelectricity mainly originates from the multi-phase coexistence constructed by shifting the orthorhombic-tetragonal phase transition temperature (Tо-т) to the room temperature [6]. Inspired by this, Wu et al. proposed a new way to construct the multi-phase coexistence by simultaneously adjusting $T \mathrm{O}-\mathrm{T}$ and rhombohedral-orthorhombic phase transition temperature $\left(T_{\mathrm{R}-\mathrm{O})}\right.$ to the room temperature after ten years, resulting in the continuous increase in piezoelectric coefficient $d_{33}$ [1,7-12]. Currently, $d_{33}$ values of state-of-the-art non-textured KNN-based ceramics are as high as 400-650 pC/N, comparable to those of commercial soft PZT-based ceramics $[1,7,11,12]$.

Although the phase boundary can be empirically obtained by trying different additives or summarizing additives from the reported investigations [13], it is still needed to further understand how additives influence the phase structure from other aspects, such as ionic radii, electronegativity, hybridization, and polarizability [13]. Thus, the current consideration or choice for additives still remains in the exploratory stage, which hinders the further development of KNN-based ceramics. When surveying the reported additives, ion substitutions (e.g., $\mathrm{Li}_{+}, \mathrm{Ag}_{+}$, $\mathrm{Sb} 5_{+}$, and $\mathrm{Ta} 5+$ ) and/or $\mathrm{ABO}_{3}$-type additives were found to effectively construct the phase boundary and obtain high $d_{33}$ values $[1,2,13]$. Particularly, $\mathrm{A}_{2}+\mathrm{B} 4+\mathrm{O}_{3}$-type additives, represented by $(\mathrm{Bi} 0.5 \mathrm{M} 0.5) \mathrm{NO}_{3}(\mathrm{M}=\mathrm{Na} / \mathrm{Ag} / \mathrm{K}, \mathrm{N}=\mathrm{Zr} / \mathrm{Hf})$, were widely utilized 
to reduce TO-т [14-16]. However, other additives, which have the same type but different combined ions, were reported to slightly influence TO-T when comparing with the former in the same content, such as $\mathrm{ABO}_{3}(\mathrm{~A}=\mathrm{Ca} / \mathrm{Ba} / \mathrm{Sr}, \mathrm{B}=\mathrm{Zr} / \mathrm{Hf})[17-20]$. The recent statistics reveal that additions of $\mathrm{Sb} 5+$ and $\mathrm{Bi} 3+$ are extremely crucial for achieving high $d_{33}$ values [13]. Therefore, it is highly speculated that Bi3+ plays a significant role in the effect of $\left(\mathrm{Bi}_{0.5} \mathrm{M}_{0.5}\right) \mathrm{NO}_{3}(\mathrm{M}=\mathrm{Na} / \mathrm{Ag} / \mathrm{K}, \mathrm{N}=\mathrm{Zr} / \mathrm{Hf})$ on $\mathrm{KNN}-$ based ceramics' Tо-т. Unfortunately, the related investigations focusing on the role of ions in additives' controlling ability are still rare, the analysis of which will substantially promote the understanding of how additives affect the phase structure of KNN-based ceramics.

To verify the abovementioned hypothesis, we choose $0.95\left(\mathrm{~K}_{0.48} \mathrm{Na} 0.52\right) \mathrm{NbO}_{3}-0.05\left(\mathrm{Bi}_{0.5} \mathrm{Ag}_{0.5}\right) \mathrm{ZrO}_{3}$ as the material matrix and $\mathrm{BaZrO}_{3}$ as the additive, that is, $0.95\left(\mathrm{~K}_{0.48 \mathrm{Na}} 0.52\right) \mathrm{NbO}_{3}-(0.05-$ $x)\left(\mathrm{Bi}_{0.5} \mathrm{Ag}_{0.5}\right) \mathrm{ZrO}_{3}-x \mathrm{BaZrO}_{3}$. Firstly, (Bi0.5 $\left.\mathrm{Ag}_{0.5}\right) \mathrm{ZrO}_{3}$ was reported to effectively reduce $T$ o-T and an increased $d_{33}$ value was obtained in $0.95\left(\mathrm{~K}_{0.48} \mathrm{Na}_{0.52}\right) \mathrm{NbO}_{3}-0.05\left(\mathrm{Bi} 0.5 \mathrm{Ag}_{0.5}\right) \mathrm{ZrO}_{3}[14,21] . \mathrm{BaZrO}_{3}$ was widely adopted in designing high-performance KNN-based ceramics but exhibited a weaker influence on $T_{\mathrm{O}-\mathrm{T}}$ than $\left(\mathrm{Bi} 0.5 \mathrm{Ag}_{0.5}\right) \mathrm{ZrO}_{3}$ in the same content $[17,22,23]$. Then, the formula actually can be treated as the substitution on $\left(\mathrm{Bi}_{0.5 \mathrm{Ag}} 0.5\right) 2+$ with $\mathrm{Ba}_{2}+$. Therefore, the designed formula can not only compare the controlling ability between $\left(\mathrm{Bi} 0.5 \mathrm{Ag}_{0.5}\right) \mathrm{ZrO}_{3}$ and $\mathrm{BaZrO}_{3}$ but also reveal the role of $\mathrm{Bi} 3+$ in (Bi0.5 $\mathrm{Ag} 0.5) \mathrm{ZrO}$. Subsequently, the phase structure is analyzed by the combined tools, including XRD patterns, Rietveld refinement, temperature-dependent dielectric properties and in situ temperaturedependent Raman spectra. The reduced degree of phase coexistence is clearly observed with increasing $\mathrm{Ba} 2+$ content, which is also reflected by electrical properties varying with composition and temperature. Finally, the analysis reveals that the reduced degree of phase coexistence is mainly attributed to the 
different electronegativity values between $\mathrm{Ba}_{2}+$ and $\mathrm{Bi} 3+$. Therefore, this work helps understand the role of ions in additives' controlling ability to the phase structure of KNN-based ceramics.

\section{Experimental procedure}

$0.95\left(\mathrm{~K}_{0.48} \mathrm{Na}_{0.52}\right) \mathrm{NbO}_{3}-(0.05-x)(\mathrm{Bi} 0.5 \mathrm{Ag} 0.5) \mathrm{ZrO}_{3}-x \mathrm{BaZrO}_{3}-0.2 w t \% \mathrm{Fe}_{2} \mathrm{O}_{3}$ (abbreviated as KNN-BAZBZ-Fe, $x=0-0.08)$ ceramics were fabricated by the solid-state method. $\mathrm{K}_{2} \mathrm{CO}_{3}(99 \%), \mathrm{Na}_{2} \mathrm{CO}_{3}(99.8 \%)$, $\mathrm{Nb}_{2} \mathrm{O}_{5}(99.5 \%), \mathrm{Bi}_{2} \mathrm{O}_{3}(99.999 \%), \mathrm{BaCO}_{3}(99.9 \%), \mathrm{Fe}_{2} \mathrm{O}_{3}(99 \%), \mathrm{Ag}_{2} \mathrm{O}(99.7 \%)$ and $\mathrm{ZrO}_{2}(99.5 \%)$ (Sinopharm Chemical Reagent Co., Ltd, China) were selected as raw materials. $0.2 w t \% \mathrm{Fe}_{2} \mathrm{O}_{3}$ was doped to promote the sinterability of $\mathrm{KNN}$-based ceramics [7]. All raw materials were dried at $180{ }_{\circ} \mathrm{C}$ for $3 \mathrm{~h}$ due to the hygroscopicity. Mixed raw materials were ball-milled for $24 \mathrm{~h}$ with zirconia ball media and alcohol in plastic jars. Then, the dried slurry was calcined at $850 \mathrm{o} C$ for $6 \mathrm{~h}$. The calcined powder was pressed into the disks of $10 \mathrm{~mm}$ diameter and $1 \mathrm{~mm}$ thickness under $10 \mathrm{MPa}$ using polyvinyl alcohol aqueous solution (PVA, $8 w t \%$ ) as a binder. After burning off the PVA at $500{ }_{\circ} \mathrm{C}$ for $5 \mathrm{~h}$, the green disks were sintered at $1060-1120{ }_{\circ} \mathrm{C}$ for $3 \mathrm{~h}$ under a corundum crucible in air. To characterize the electrical properties of ceramics, the silver paste was printed on both sides of the assintered disks, which were then baked at 600 oC for $30 \mathrm{~min}$ to form electrodes. Finally, the coatedsamples were poled under a direct current (DC) electric field of $40 \mathrm{kV} / \mathrm{cm}$ for $30 \mathrm{~min}$ in a silicone oil bath at room temperature.

The crystal information was collected from the as-sintered ceramics by using an X-ray diffraction (XRD) instrument (Bruker D8 Advance XRD, BrukerAXS Inc., Madison, WI, Cu-Ka). To collect the powder XRD data, as-sintered samples were crushed and then manually ground for 2 hours. The obtained powder was thermally treated at $600{ }_{\circ} \mathrm{C}$ for 2 hours in a furnace to get rid of the internal stress during the grinding process. The powder XRD data was collected using a high-resolution XRD equipment (DY120, PANalytical, Netherlands) and the Material Analysis Using Diffraction (MAUD) 
software was used to conduct the full-pattern fitting [24,25]. To conduct the grain size and energy dispersion spectrum (EDS) analysis, surfaces of as-sintered samples were manually polished by using the diamond suspension liquid and then heated at $1000{ }_{\circ} \mathrm{C}$ for 10 minutes. The surface morphology and EDS data of polished samples were collected by a field emission scanning electron microscope (Merlin, Zeiss, Germany). in situ temperature-dependent Raman spectra were measured by a Raman equipment (Horiba Aramis, Horiba Scientific, Japan) with the excitation source of $473 \mathrm{~nm}$ radiation, in connection with an external temperature controller (HFS600E-PB4/PB2, Linkam Scientific Instruments, UK). The direct piezoelectric coefficient ( $\left.d_{33}\right)$ of poled samples was measured by a quasistatic $d_{33}$ meter (ZJ-3 A, China) after aging for 24 hours. in situ small signal $d_{33}$ values were collected by self-built equipment [26]. Poled samples were put into a furnace that was coupled with a laser system (Politec sensor head OFV-505 and front-end VDD-E-600). A sinusoidal alternating current (AC) voltage of $\pm 10 \mathrm{~V}$ with a frequency of $1 \mathrm{kHz}$ was applied on the poled samples, which generated the displacement that was recorded by the laser system. Therefore, the equipment actually measured the converse piezoelectric effect. A more detailed description of the measurement's principle was referred to ref. [26]. Temperature-dependent relative permittivity $(\varepsilon r-T)$ curves were measured by a broadband dielectric spectrometer (Novocontrol Concept 80, Novocontrol, Germany). Polarization-electric field $(P-E)$ loops, bipolar strain-electric field $(S-E)$ curves, and unipolar strain curves were measured via a ferroelectric analyzer (aixACCT TF Analyzer 2000, Germany) with a laser interferometer vibrometer (SP-S120/500, SIOS Meßtechnik GmbH, Germany), at a frequency of $1 \mathrm{~Hz}$.

\section{Results and discussion}

Figure 1(a) shows the composition-dependent XRD patterns of KNN-BAZ-BZ-Fe ceramics, measured at room temperature. All samples exhibit the typical perovskite structure without the obvious secondary phase, suggesting the additives have diffused into KNN ceramics' lattice. $\{100\}$ pc and 
$\{200\}$ pc diffractions are enlarged to show the variation of the phase structure (Figures $1(\mathrm{~b}, \mathrm{c})) .(200)_{\mathrm{pc}}$ (or $(100)$ pc) peak has a twice intensity higher than $(002)$ pc (or $(001)$ pc) peak, indicating the involvement of a T phase [18]. With an increasing $x,(200)$ pc $((002)$ pc $)$ peaks show a decreasing (increasing) intensity, resulting in the intensity of $(002)$ pc peak is twice as high as that of (200)pc peak at $x=0.03$. A similar variation is also observed in $\{100\}$ pc diffractions, manifesting the occurrence of an O phase [27].
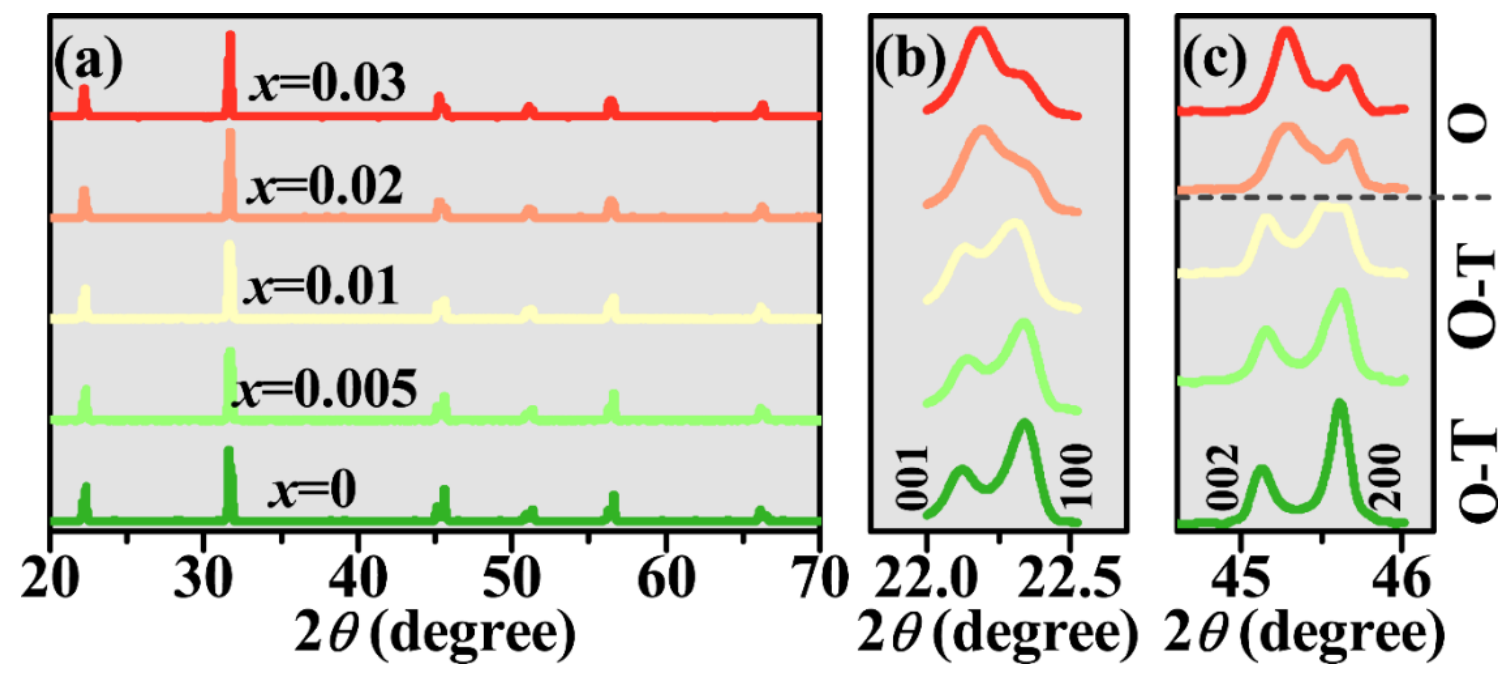

Figure 1. Composition-dependent XRD patterns of KNN-BAZ-BZ-Fe ceramics with (a) $2 \theta=20-70$, (b) $2 \theta=22-22.5$ o, and (c) $2 \theta=45-46$ o.

To further show the variation of phase content, $\{200\}$ pc diffractions are fitted by the Lorentz fitting (Figures 2(a-e)) [28-30]. All fittings show a good fit between the raw data and the fitted data. The phase content obtained from the Lorentz fitting is plotted in Figure 2(f). With an increasing $x$, the phase structure progressively changes from the coexisting $\mathrm{O}-\mathrm{T}$ phases to a single $\mathrm{O}$ phase, indicating the reduced degree of phase coexistence. 

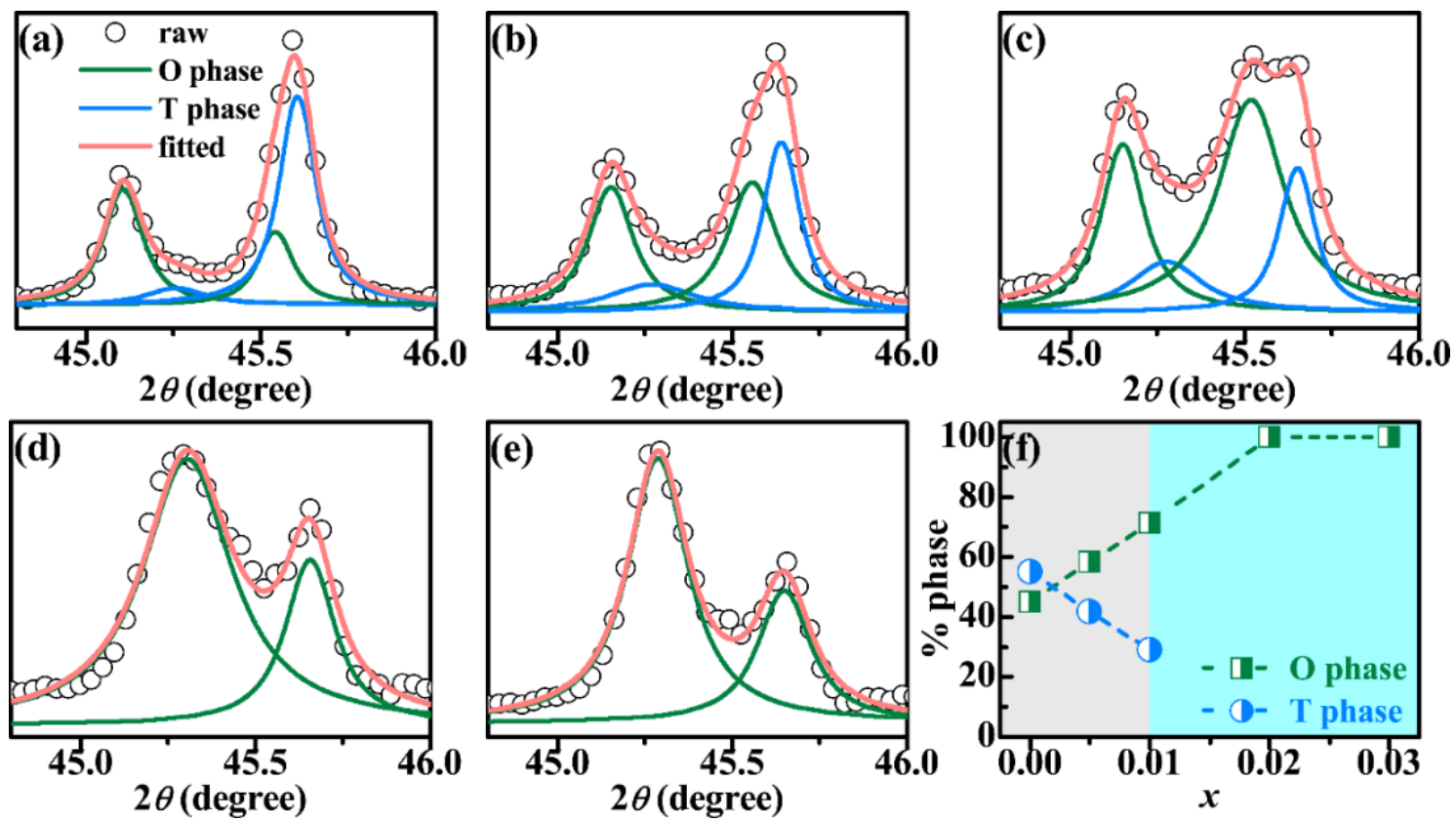

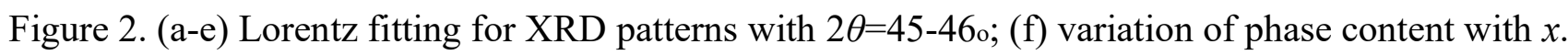

To further reflect the reduced degree of phase coexistence, the full-pattern fittings using the Rietveld method are carried out on the powder XRD patterns (see Figures 3 and S1, Supplementary Material). All refinements show a good match between the raw data and the fitting one (Figure 3), which are

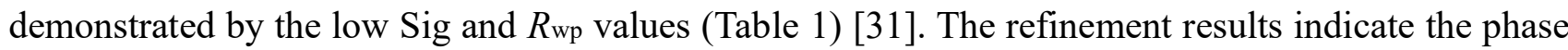
transition from coexisting $\mathrm{O}-\mathrm{T}$ phases to an $\mathrm{O}$ phase and obtained variations of phase fraction also coincide with those extracted from the Lorentz fitting (Figure 2(f)). Therefore, the substitution on $\left(\mathrm{Bi} 0.5 \mathrm{Ag}_{0.5}\right)_{2}+$ with $\mathrm{Ba}_{2}+$ indeed reduces the degree of phase coexistence. In addition, compositiondependent and in situ temperature-dependent Raman spectra also demonstrate the reduced degree of phase coexistence (Figures S2 and S3, Supplementary Material). 

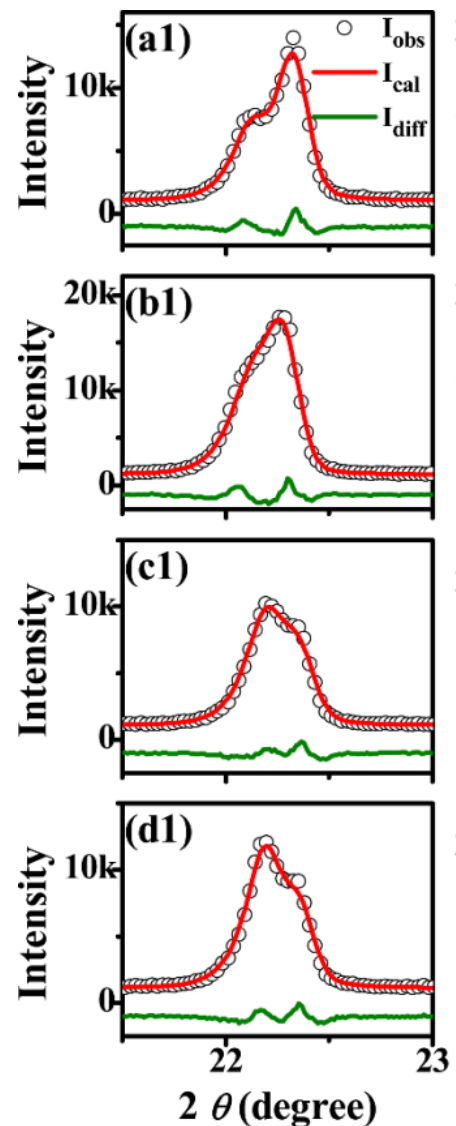
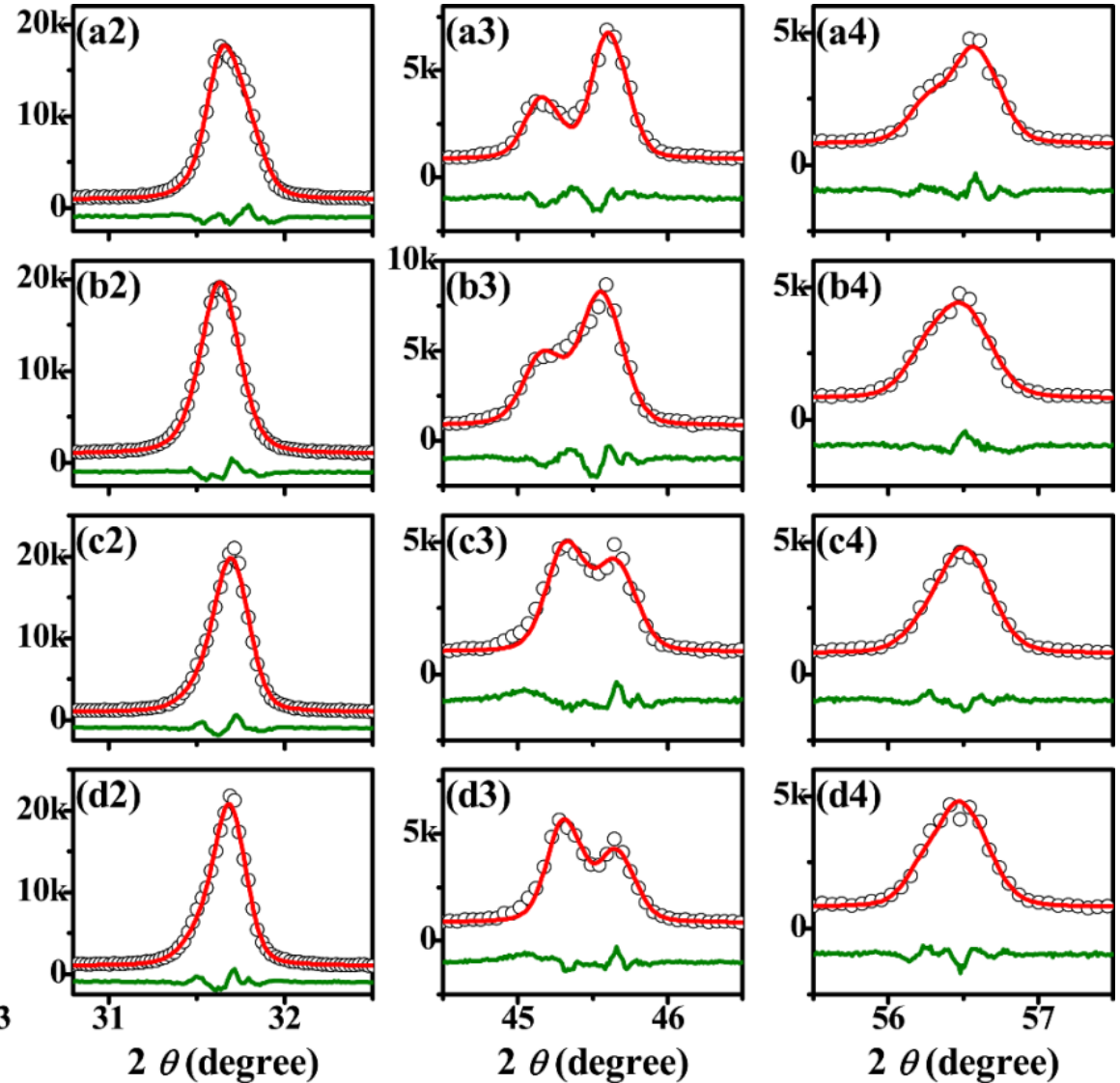

Figure 3. Full-pattern fittings for powder XRD data of the ceramics with $x=0$ (a1-a4), 0.01 (b1-b4), 0.02 (c1-c4), and 0.03 (d1-d4). Iobs, Ical, and Idiff respectively represent the observed data (i.e., raw data), the calculated data (i.e., fitting data), and the difference between them.

Generally, the composition-dependent phase structure can also be identified by $\varepsilon r-T$ curves [32]. With an increasing $x$, TO-T gradually increases from $44{ }_{\circ} \mathrm{C}$ (at $x=0$ ) to $118{ }_{\circ} \mathrm{C}$ (at $x=0.03$ ) and $T$ R-o slightly increases from $-50{ }_{\circ} \mathrm{C}$ to $-36{ }_{\circ} \mathrm{C}$ (Figures $4(\mathrm{a}-\mathrm{e})$ ). Therefore, the ceramics with $x=0-0.01$ possess coexisting $\mathrm{O}-\mathrm{T}$ phases because their TO-T values are close to the room temperature, and the ceramics with $x=0.02-0.03$ exhibit an $\mathrm{O}$ phase due to a much higher $T_{\mathrm{O}-\mathrm{T}}$ than the room temperature (Figures 4(a-e)). Interestingly, the Curie temperature $\left(T_{\mathrm{c}}\right)$ slightly reduces as $x$ increases, being within 310-330 ${ }_{\mathrm{o}} \mathrm{C}$ (Figure 4(f)). Therefore, (Bi0.5 $\left.\mathrm{Ag}_{0.5}\right) \mathrm{ZrO}_{3}$ possesses a more pronounced ability to affect $\mathrm{To}_{\mathrm{O}} \mathrm{T}$ than $\mathrm{BaZrO}_{3}$ without significantly sacrificing $T_{\mathrm{c}}$. The modified Curie-Weiss law is further used to examine 
the variation of relaxor degree

$$
\frac{1}{\varepsilon(T)}-\frac{1}{\varepsilon_{m}}=\frac{\left(T-T_{m}\right)^{\gamma}}{C}
$$

where $\varepsilon \mathrm{m}$ is the maximum value of dielectric permittivity at $T \mathrm{~m}, C$ is the Curie-like constant, and $\gamma$ represents the relaxor degree [33]. Classical ferroelectrics and ideal relaxors have a $\gamma$ of 1 and 2, respectively [33]. Figure $4(\mathrm{~g})$ shows an example of the linear fitting between $\ln \left(T-T_{\mathrm{m}}\right)$ and $\ln \left(1 / \varepsilon_{\mathrm{r}}-\right.$ $1 / \varepsilon \mathrm{m}$ ) for the ceramic with $x=0$. With an increasing $x, \gamma$ slightly reduces from 1.31 to $1.26 \sim 1.28$, indicating the slightly decreased relaxor degree (Figure 4(i)). In addition, the Curie-Weiss law is also considered

$$
\varepsilon_{\mathrm{r}}=C\left(T-T_{\mathrm{o}}\right)-1\left(T>T_{\mathrm{o}}\right)
$$

where $T_{\mathrm{o}}$ is the Curie-Weiss temperature and $\mathrm{C}$ is the Curie-Weiss constant [34]. Figure 4(h) displays the relationship between the inverse $\varepsilon_{\mathrm{r}}\left(104 / \varepsilon_{\mathrm{r}}\right)$ and temperature for the sample with $x=0$. Obviously, the Curie Weiss law is well obeyed at a temperature $(T \mathrm{Cw})$ higher than $T \mathrm{~m}$. Thus, the difference between $T_{\mathrm{CW}}$ and $T_{\mathrm{m}}\left(\Delta T=T_{\mathrm{CW}}-T_{\mathrm{m}}\right)$ was also used to evaluate the relaxor degree [34]. With an increasing $x$, $\Delta T$ decreases from $65{ }_{\circ} \mathrm{C}$ to $50 \sim 55{ }_{\circ} \mathrm{C}$, further indicating the slightly decreased relaxor degree. It is inferred that $\mathrm{Ba}_{2}+$ exhibits a weaker effect in increasing the relaxor degree of $\mathrm{KNN}$ ceramics than (Bi0.5Ag0.5)2+. Therefore, the substitution on (Bi0.5Ag0.5)2+ with Ba2+ successfully reflects their controlling ability to the phase transition temperature and relaxor degree. 

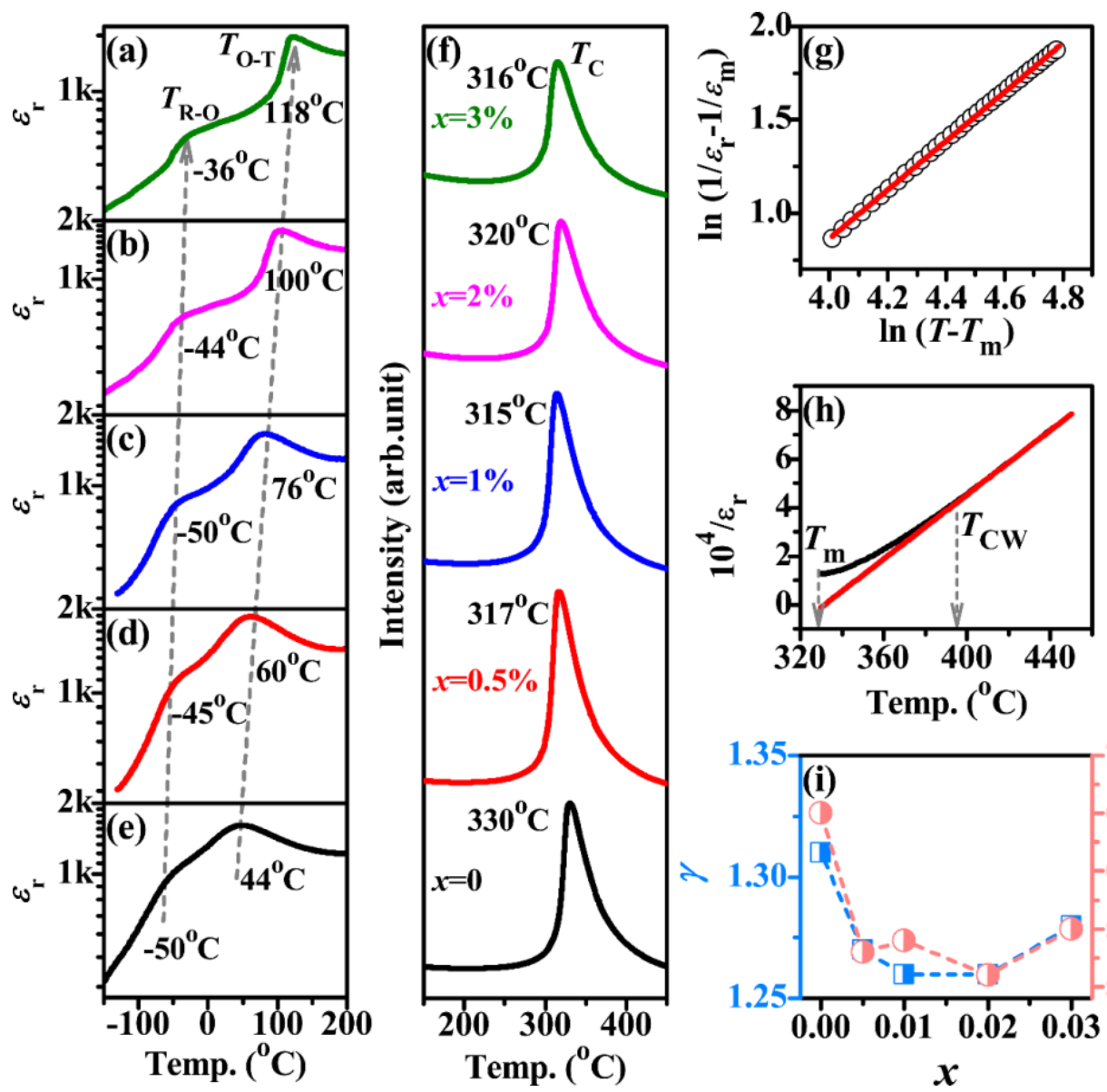

Figure 4. (a-f) $\varepsilon \mathrm{r}-T$ curves of KNN-BAZ-BZ-Fe; (g) linear fitting between $\ln \left(T-T_{\mathrm{m}}\right)$ and $\ln \left(1 / \varepsilon_{\mathrm{r}}-1 / \varepsilon_{\mathrm{m}}\right)$ for $x=0$; (h) relationship between temperature and $104 / \varepsilon$; (i) variations of $\gamma$ and $\Delta T$ with $x$.

Figures 5(a-c) show the surface morphology of the ceramics after polishing and thermal etching. Clearly, the grain size monotonically reduces with increasing $x$. The corresponding grain size distributions are collected (Figures 5(d-f)). The average grain size (AGS) reduces from $3.75 \mu \mathrm{m}$ (for $x=0$ ) to $1.99 \mu \mathrm{m}$ (for $x=0.03)$. Therefore, $\mathrm{Ba}_{2}+$ inhibits grain growth compared to $\left(\mathrm{Bi}_{0.5} \mathrm{Ag}_{0.5}\right)_{2+}$. Figure 6 shows the EDS analysis of the ceramics with $x=0,0.01$, and 0.03 . All elements are detected in these ceramics and the increasing content of $\mathrm{Ba}_{2}+$ is also observed. The peaks in EDS, which represent the photon energy associated with electron transitions between L-shell and K-shell in Ba atoms, occur in the ceramics with $x=0.01$ and their intensities heighten as $x$ further increases to 0.03 (Figures 6(a2, b2, 
c2)). In addition, the atomic percentage also demonstrates the increased content of Ba element (Figures 6(a3, b3, c3)).
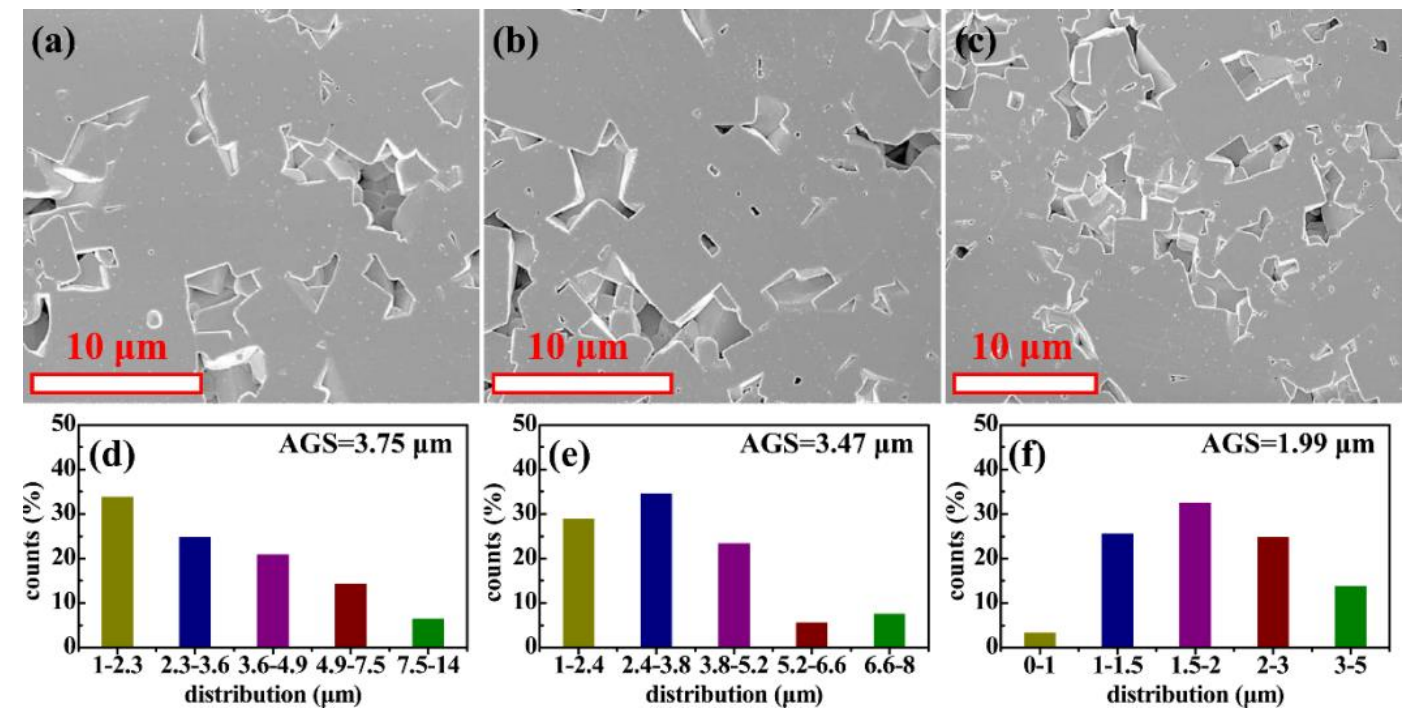

Figure 5. Surface morphology and grain size distribution of the polished specimens with $x=0$ (a, d), $0.01(\mathrm{~b}, \mathrm{e})$, and $0.03(\mathrm{c}, \mathrm{f})$.
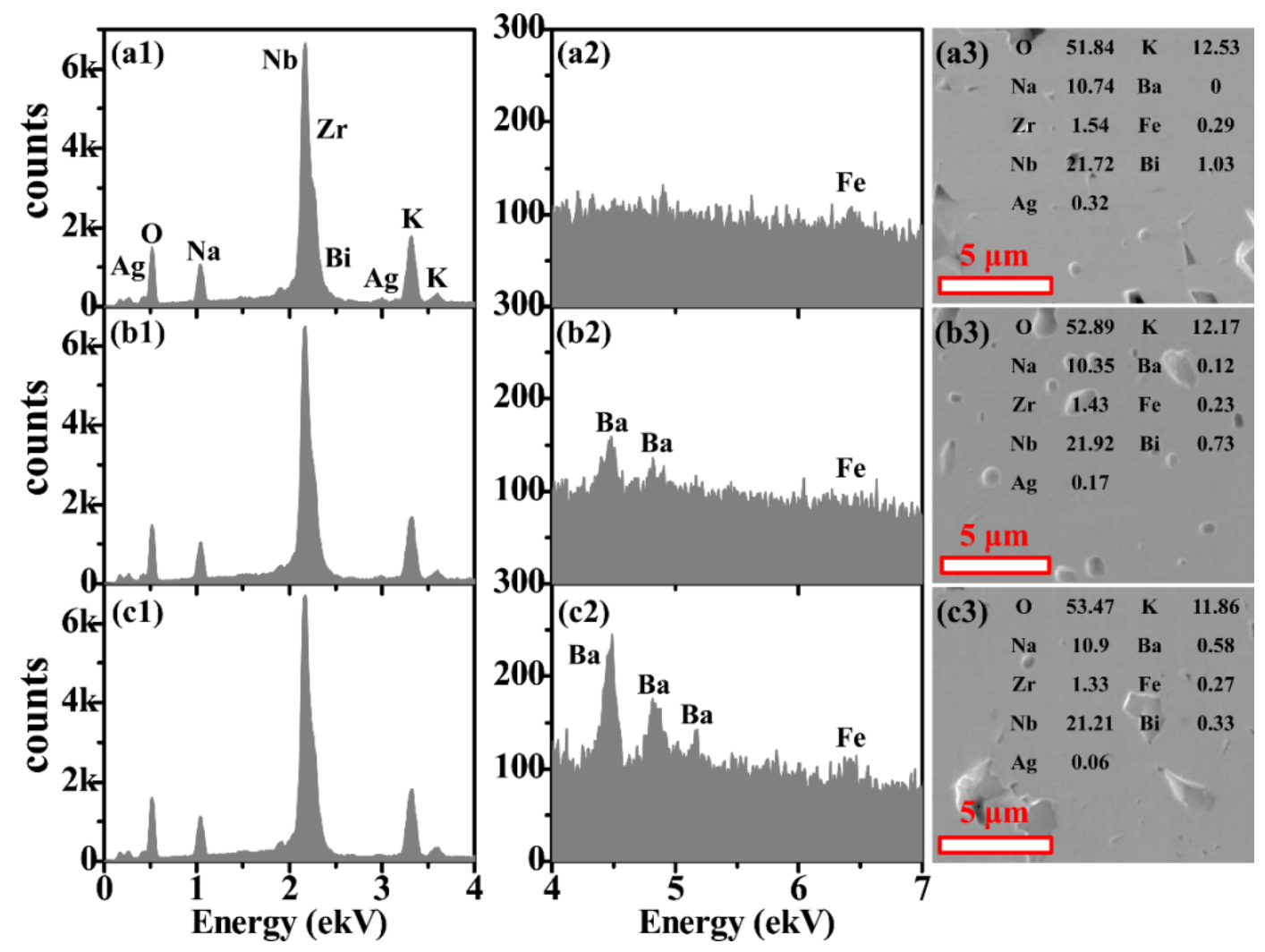

Figure 6. EDS analysis and correspondingly selected areas of the polished ceramics with $x=0$ (a1-a3), 
0.01 (b1-b3), and 0.03 (c1-c3). The insets in $(\mathrm{a} 3, \mathrm{~b} 3, \mathrm{c} 3)$ show the element atomic percentage.

As is well known, electrical properties will be enhanced in the multi-phase coexistence region $[1,5]$. Therefore, the decreased electrical properties are highly anticipated in KNN-BAZ-BZ-Fe ceramics due to the reduced degree of phase coexistence. Indeed, $d_{33}$ value monotonically decreases with $x$ (Figure 7(a)). Generally, the piezoelectricity of perovskite ferroelectrics can be expressed as

$$
d_{33}=2 Q_{33 \varepsilon \mathrm{r}} P_{\mathrm{r}}
$$

where $Q_{33}$ is the electrostriction coefficient, $\varepsilon \mathrm{r}$ is the dielectric permittivity, and $P_{\mathrm{r}}$ is the remanent polarization [35]. $Q_{33}$ is closely related to the order degree of cation arrangements [36]. Due to the similar $\gamma, d_{33}$ values are mainly determined by $\varepsilon_{\mathrm{r}} P_{\mathrm{r}}$, which is the reason why $d_{33}$ and $\varepsilon_{\mathrm{r}} P_{\mathrm{r}}$ show a similar variation with $x$ (Figure 7(a)). Therefore, the reduced degree of phase coexistence significantly decreases $\varepsilon$ r and $P_{\mathrm{r}}$, resulting in a decreased $d_{33}$. in situ temperature-dependent small signal $d_{33}$ measurements are shown in Figure 7(b). For each composition, two anomalies are observed with the increasing temperature. The first anomaly is caused by To-T, and the second one is widely treated as the depolarization temperature $\left(T_{\mathrm{d}}\right)$, which is generally slightly lower than $T_{\mathrm{c}}$ [37]. The observed $T_{\mathrm{O}-\mathrm{T}}$ values are highly consistent with the ones extracted from $\varepsilon r-T$ curves (Figures 4(a, c, e)). Figure 7(c) shows the unipolar strain curves of KNN-BAZ-BZ-Fe ceramics. The unipolar strain (Suni) monotonically decreases with an increasing $x$ (Figure $7(\mathrm{~d})$ ), suggesting the decreasing converse piezoelectric response and non-180o domain switching [38]. 

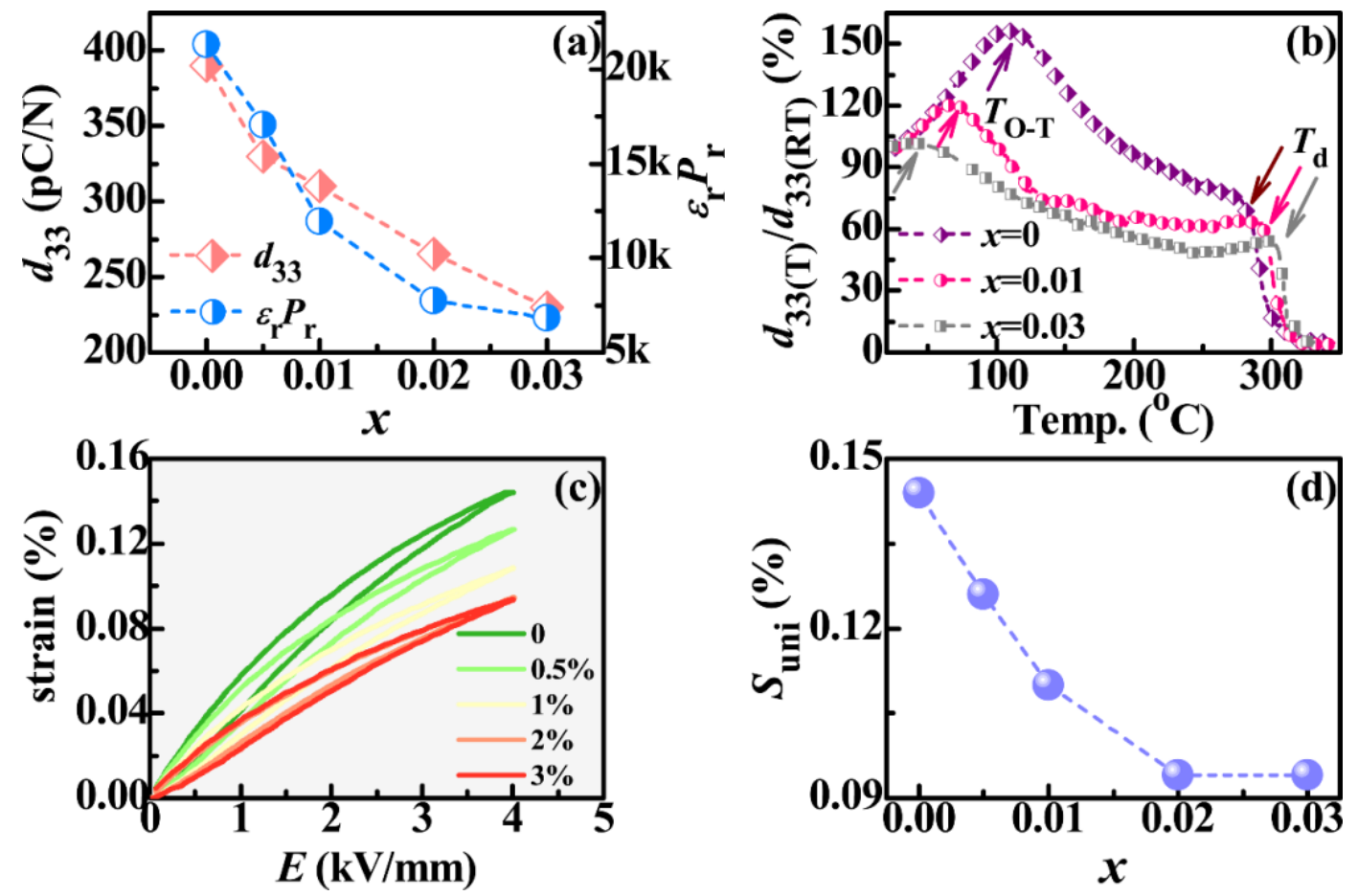

Figure 7. (a) Variations of $d_{33}$ and $\varepsilon_{\mathrm{r}} P_{\mathrm{r}}$ with $x$; (b) variation of in situ small signal $d_{33}$ with temperature;

(c) unipolar strain curves and (d) $S_{\text {uni }}$ of KNN-BAZ-BZ-Fe ceramics.

Figures $8(\mathrm{a}, \mathrm{b})$ show the ferroelectric hysteresis $(P-E)$ loops and bipolar strain curves of KNN-BAZBZ-Fe ceramics. Variations of $P_{\mathrm{r}}$, coercive field $\left(E_{\mathrm{c}}\right)$, negative strain $\left(S_{\mathrm{neg}}\right)$, positive strain $\left(S_{\mathrm{pos}}\right)$, and poling strain $\left(S_{\mathrm{pol}}\right)$ are listed in Figures $8(\mathrm{c}, \mathrm{d})$. With an increasing $x, E_{\mathrm{c}}$ and $P_{\mathrm{r}}$ monotonically reduce, indicating the decreased ferroelectricity. Meanwhile, $S_{\text {neg, }} S_{\text {pos, }}$ and $S_{\text {pol }}$ also monotonically decrease with an increasing $x$, suggesting the deteriorative converse piezoelectric response and non-180o domain switching [38]. Generally, the coexisting O-T phases possess lower polarization anisotropy and more polarization variants than the O phase [39]. Therefore, the reduced degree of phase coexistence (i.e., from coexisting $\mathrm{O}-\mathrm{T}$ phases to an $\mathrm{O}$ phase) will necessarily worsen the ferroelectric and strain properties. Here, it is worth noting that the enhanced electrical properties are still observed at $x=0.03$ despite the reduced AGS and the reduced degree of phase coexistence. It was reported that the piezoelectricity was enhanced by the increasing grain size and the construction of multi-phase 
coexistence [32,39]. As compared in Table 2, the ceramics with $x=0.03$ show the superior electrical properties to those of other KNN-based ceramics with an AGS of 1-2 $\mu$ m [32,40-43]. Particularly, some of the other ceramics even possess the coexisting O-T or R-T phases [32,40-43]. Therefore, the substitutions among different additives may provide more options for inducing the desired electrical properties.
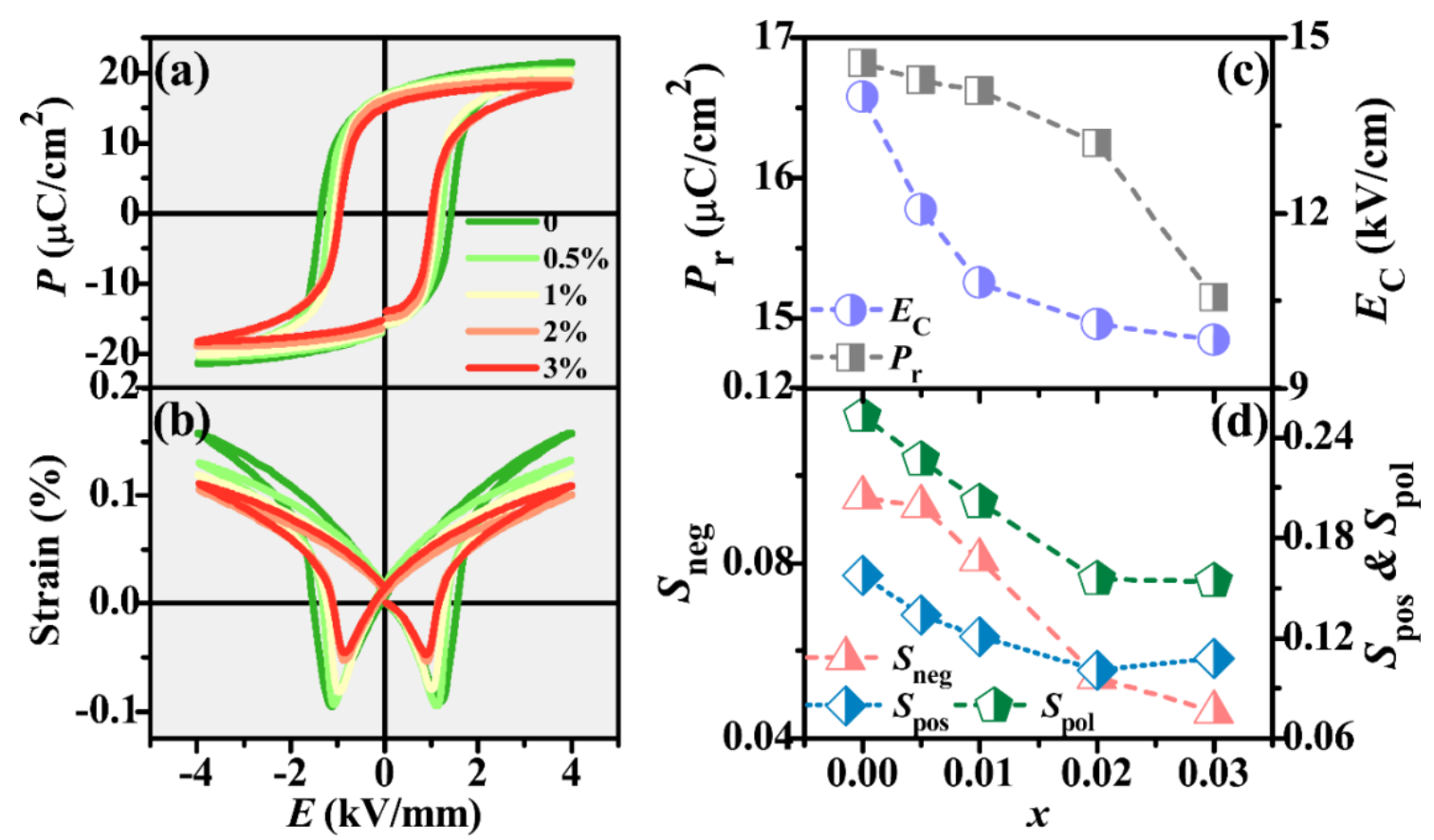

Figure 8. (a) P-E loops and (b) bipolar strain curves of KNN-BAZ-BZ-Fe ceramics; corresponding variations of (c) $E_{\mathrm{c}}, P_{\mathrm{r}},(\mathrm{d}) S_{\mathrm{neg}}, S_{\mathrm{pos}}$, and $S_{\mathrm{pol}}$.

Considering the increased $T_{\mathrm{O}-\mathrm{T}}$, the anomaly in temperature-dependent $S_{\text {uni }}$ will also shift to a higher temperature. Figures $9(\mathrm{a}-\mathrm{c})$ show the temperature-dependent unipolar strain curves of the ceramics with $x=0-0.03$. The variations of normalized $S$ uni are plotted in Figure $9(\mathrm{~d})$. For $x=0, S_{\text {uni first increases }}$ slightly at 20-60 ${ }_{\circ} \mathrm{C}$ and then reduces at $60-180{ }_{\circ} \mathrm{C}$, resulting in the anomaly at $\sim 60{ }_{\circ} \mathrm{C}$ close to it $T \mathrm{O}-\mathrm{T}$ $\left(\sim 44{ }_{\circ} \mathrm{C}\right)$. The similar anomalies are also observed to be at $80{ }_{\circ} \mathrm{C}$ for $x=0.01$ and $120{ }_{\circ} \mathrm{C}$ for $x=0.03$, which coincide with their TO-T values. Therefore, the reduced degree of phase coexistence is also 
reflected by the temperature-dependent $S_{\text {uni. }}$
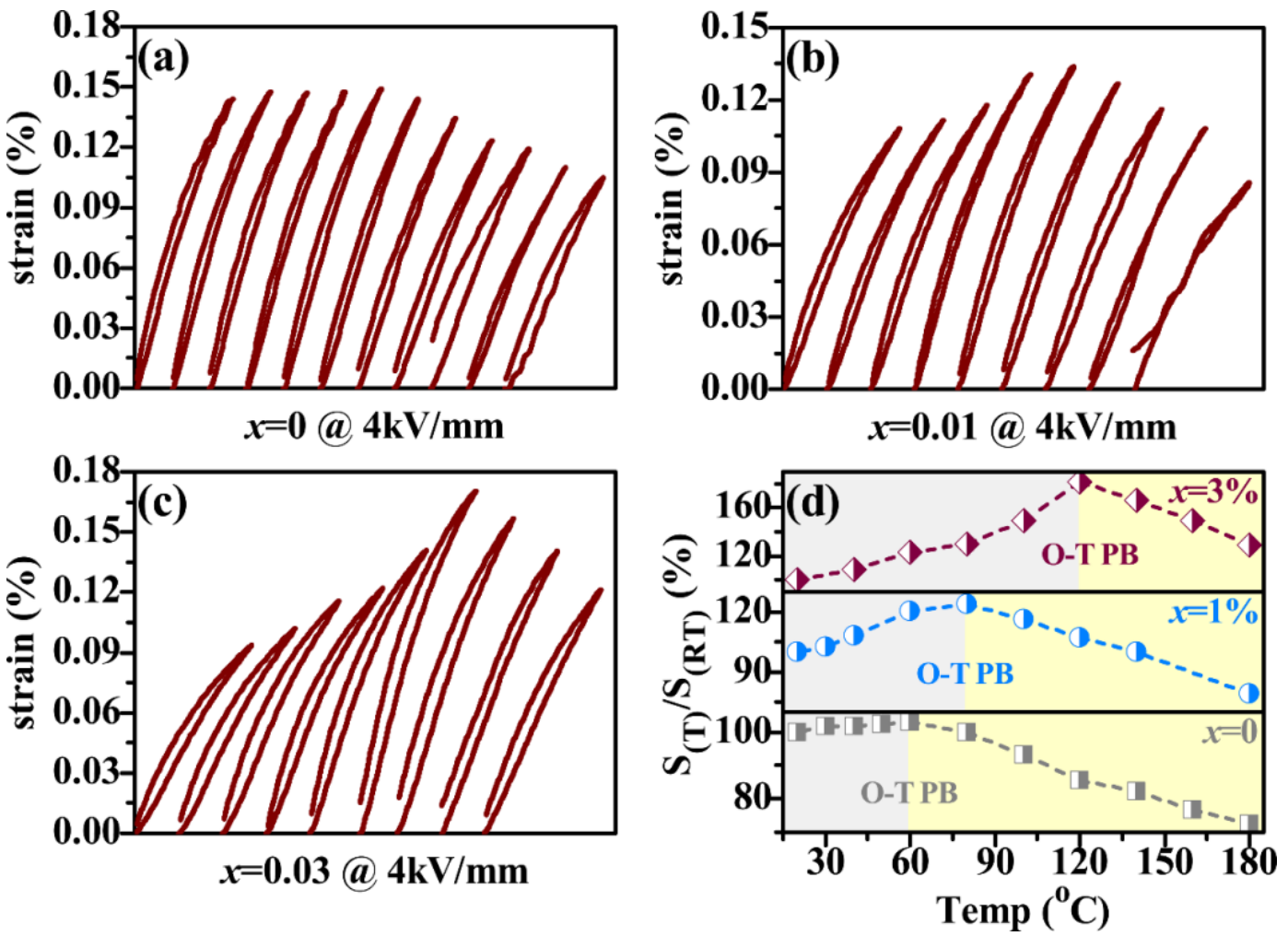

Figure 9. Temperature-dependent unipolar curves of KNN-BAZ-BZ-Fe ceramics with (a) $x=0$, (b) $x=0.01$, and (c) $x=0.03 ;(d)$ variations of $S$ uni with temperature.

Therefore, both the structural analysis and electrical properties confirm that the substitution on (Bi0.5Ag0.5)2+ with $\mathrm{Ba} 2+$ indeed restores the coexisting $\mathrm{O}-\mathrm{T}$ phases to an $\mathrm{O}$ phase. Here, the reduced degree of phase coexistence and the decrease in AGS are ascribed to the ion radius and competing ionic/covalent bonding between $\left(\mathrm{Bi}_{0.5} \mathrm{Ag}_{0.5}\right)_{2+}$ and $\mathrm{Ba}_{2+}$, as shown in Figure 10. For electronegativity, the percentage of covalent bonds is evaluated by

$$
C \%=e^{-0.25\left(X_{A}-X_{B}\right)^{2} \times 100 \%}
$$

where $X_{\mathrm{A}}$ and $X_{\mathrm{B}}$ are the electronegativity values of two different elements [13]. The ion radius, electronegativity, and bonding fraction with the oxygen of A-site ions are listed in Table 2. Both (Bi0.5Ag0.5)2+ and Ba2+ were deemed to occupy the A-site of KNN ceramics, belonging to the 
heterovalent substitutions $[14,21,44]$. Heterovalent substitutions were reported to greatly enhance the relaxor degree, and the large ionic radius difference would further disrupt the long-range order and thus promote the relaxor degree [45]. Therefore, a $\gamma$ of 1.31 is observed at $x=0$, which is much higher than that of pristine KNN ceramics [34]. While the substitution on (Bi0.5Ag0.5)2+ with $\mathrm{Ba} 2+$ reduces the ionic radius difference between $\mathrm{K}+/ \mathrm{Na}+$ and other ions (see Table 3 ), which is the reason why $\gamma$ slightly reduces from 1.31 to $1.26 \sim 1.28$. For KNN-based ceramics, it was reported that the substitution on Asite with $\mathrm{Ba} 2+$ monotonically reduced the grain size, while the slight addition of $\mathrm{Bi}_{2} \mathrm{O}_{3}$ could promote the grain growth and increase the density [46]. Therefore, the monotonic decrease in AGS is mainly attributed to the increasing content of $\mathrm{Ba}_{2}+$.

Then, the electronegativity is considered for explaining the phase structure. The Ba-O bonding results in the strong ionic bond character, while $\mathrm{Bi}-\mathrm{O} / \mathrm{Ag}-\mathrm{O}$ bonding weakens the ionic bond and enhances the covalent bond characters, particularly the high electronegativity of Bi. Therefore, it is speculated that the reduced $T_{\mathrm{O}-\mathrm{T}}$ is mainly ascribed to the substitution on A-site with Bi3+. Previously, the slight addition of $\mathrm{Zr}_{4+}$ ( or $\mathrm{ZrO}_{2}$ ) was reported to hardly decrease $T$ O-T and even slightly increase $T \mathrm{O}-\mathrm{T}$, which well verifies the speculation $[41,47]$. The decreased To-T may be attributed to the increased covalent bond character caused by Bi-O bonding, which could enhance the stabilization of the $\mathrm{T}$ phase. Therefore, the gradually increased TO-T is reasonably anticipated if one reduces the content of Bi3+, which is demonstrated in this work and other studies [48-50]. When progressively replacing Bi3+ with isovalent ions (such as $\mathrm{Sm}_{3}+, \mathrm{La}_{3}+$, and $\mathrm{Ho}_{3}+$ ), the monotonic increase in phase transition temperatures (e.g., rhombohedral-tetragonal phase transition temperature $T_{\mathrm{R}-\mathrm{T}}$ and $T_{\mathrm{O}-\mathrm{T}}$ ) was clearly observed [4850]. $\mathrm{Sm}_{3+}$, $\mathrm{La}_{3}+$, and $\mathrm{Ho}_{3}+$ show the comparable ion radius but the much lower electronegativity to $\mathrm{Bi}_{3+}$ 
(see Table 3), resulting in the still strong ionic bond character in $\mathrm{Sm}-\mathrm{O} / \mathrm{La}-\mathrm{O} / \mathrm{Ho}-\mathrm{O}$ bonding. Therefore, all the evidence demonstrates the reduced TO-T originates from the high electronegativity of $\mathrm{Bi}$. Actually, this work not only compares the controlling ability of $\mathrm{Ba} 2+$ and ( $\mathrm{Bi} 0.5 \mathrm{Ag} 0.5) 2+$ to $\mathrm{TO}_{\mathrm{O}-\mathrm{T}}$ but also significantly reveals which and how elements cause the reduced TO-T, further promoting the understanding of the role of additives on the phase structure. Particularly, previous investigations only revealed the role empirically from $\varepsilon_{\mathrm{r}}-T$ curves without further analyzing the underlying physical origin $[1,2]$. However, there is still a long way to completely understand the effects of additives on the phase structure of KNN-based ceramics, which needs more efforts in the future.

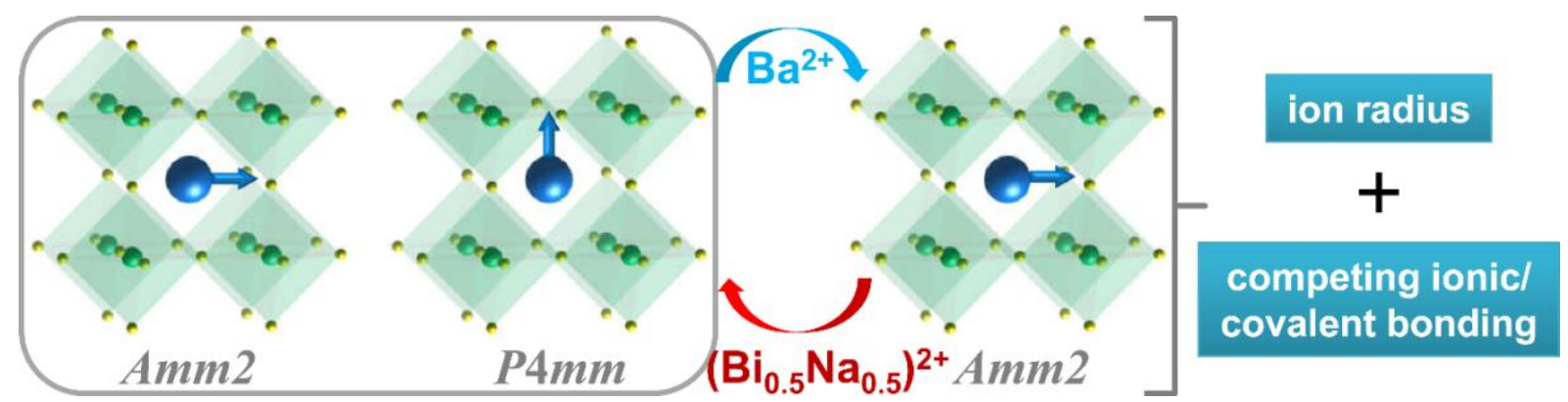

Figure 10. A schematic illustration explaining the effects of the substituting (Bi0.5Ag0.5)2+ with $\mathrm{Ba}_{2}+$ on the phase structure of KNN-BAZ-BZ-Fe ceramics.

Table 1. Results of full-pattern fittings for the powder XRD patterns.

\begin{tabular}{|c|c|c|c|c|c|c|c|}
\hline \multirow{2}{*}{$x$} & \multirow{2}{*}{ Phase } & \multirow{2}{*}{$\begin{array}{c}\text { Content } \\
(\%)\end{array}$} & \multicolumn{3}{|c|}{ Lattice parameter } & \multirow{2}{*}{ Sig } & \multirow{2}{*}{$R_{\mathrm{wp}}(\%)$} \\
\hline & & & $a(\AA)$ & $b(\AA)$ & $c(\AA)$ & & \\
\hline \multirow{2}{*}{0} & $\mathrm{O}$ & 44.7 & 3.8452 & 5.0303 & 6.2135 & \multirow{2}{*}{1.68} & \multirow{2}{*}{5.05} \\
\hline & $\mathrm{T}$ & 55.3 & 3.9753 & 3.9753 & 4.0123 & & \\
\hline \multirow{2}{*}{0.01} & $\mathrm{O}$ & 67.5 & 3.9840 & 5.2810 & 6.0415 & \multirow{2}{*}{1.65} & \multirow{2}{*}{4.81} \\
\hline & $\mathrm{T}$ & 32.5 & 3.9807 & 3.9807 & 4.0115 & & \\
\hline 0.02 & $\mathrm{O}$ & 100 & 3.9712 & 5.6388 & 5.6724 & 1.69 & 5.09 \\
\hline 0.03 & $\mathrm{O}$ & 100 & 3.9711 & 5.6407 & 5.6728 & 1.69 & 5.07 \\
\hline
\end{tabular}


Table 2. Electrical properties of KNN-based ceramics with an AGS of 1-2 $\mu \mathrm{m}$.

\begin{tabular}{|l|c|c|c|c|c|c|}
\hline Material system & AGS $(\mu \mathrm{m})$ & $d_{33}(\mathrm{pC} / \mathrm{N})$ & $\varepsilon_{\mathrm{r}}$ & $P_{\mathrm{r}}(\mu \mathrm{C} / \mathrm{cm} 2)$ & Phase & Ref \\
\hline$\left(\mathrm{K}_{0.5 \mathrm{Na} 0.5) \mathrm{O}_{3}}\right.$ & 1.96 & 104 & 328 & 12.8 & $\mathrm{O}$ & 40 \\
\hline$\left(\mathrm{K}_{0.5 \mathrm{Na} 0.5) 1-2 x \mathrm{Sr}_{x} \mathrm{NbO}_{3}(x=0.2)}\right.$ & 0.87 & - & $\sim 1000$ & - & $\mathrm{O}$ & 42 \\
\hline KNLNS- $x \mathrm{BT}(x=0.02)$ & $\sim 1$ & 150 & 1100 & - & $\mathrm{O}$ & 43 \\
\hline KNL-(NTS $) 1-x \mathrm{Zr} 5 x / 4(x=0.01)$ & $1.3 \pm 0.7$ & 220 & 870 & 18 & O-T & 41 \\
\hline KNL-(NTS $) 1-x \mathrm{Zr} 5 x / 4(x=0.03)$ & $0.8 \pm 0.4$ & 115 & 917 & 14 & O-T & 41 \\
\hline 95KNNS-1CZ-4BKHT & 1.04 & 295 & 2506 & 14.9 & R-T & 32 \\
\hline KNN-BAZ- $x \mathrm{BZ}-\mathrm{Fe}(x=0.03)$ & 1.99 & 230 & 450 & 15.2 & O & This work \\
\hline
\end{tabular}

Table 3. The ion radius, electronegativity, and bonding fraction with the oxygen of A-site ions.*

\begin{tabular}{lcccc}
\hline Ions & Radius $(\mathrm{nm})$ & Electronegativity & $\mathrm{I} \%$ & $\mathrm{C} \%$ \\
\hline $\mathrm{Na}+$ & 0.139 & 0.93 & 79.30 & 20.70 \\
$\mathrm{~K}+$ & 0.164 & 1.93 & 82.02 & 17.98 \\
$\mathrm{Ag}+$ & $\sim 0.115$ & 2.02 & 56.55 & 43.45 \\
$\mathrm{Bi}^{+}+$ & 0.103 & 0.89 & 39.60 & 60.40 \\
$\mathrm{Ba}^{+}+$ & 0.161 & 1.10 & 80.32 & 19.68 \\
$\mathrm{La}^{+}$ & 0.0901 & 1.17 & 74.56 & 25.44 \\
$\mathrm{Ho}_{3+}$ & 0.1032 & 1.23 & 70.51 & 29.49 \\
$\mathrm{Sm}_{3+}$ & 0.0958 & & 72.42 & 27.58 \\
\hline
\end{tabular}

* The bonding fraction means the percentage of ionic bond and covalent bond when these A-site ions form the bonding with the oxygen element (O). I\% and $\mathrm{C} \%$ represent the percentage of ionic bond and covalent bond, respectively.

\section{Conclusions}

In this work, $0.96\left(\mathrm{~K}_{0.48} \mathrm{Na}_{0.52}\right) \mathrm{NbO}_{3}-(0.04-x)\left(\mathrm{Bi} 0.5 \mathrm{Ag}_{0.5}\right) \mathrm{ZrO}_{3}-x \mathrm{BaZrO}_{3}-0.2 w t \% \mathrm{Fe}_{2} \mathrm{O}_{3}$ ceramics are taken as an example to unveil the role of additives on the phase structure of KNN-based ceramics. The

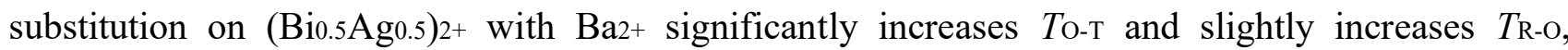

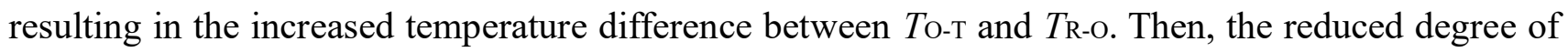
phase coexistence (i.e., from coexisting O-T phases to an $\mathrm{O}$ phase) is observed with an increasing $x$, which is demonstrated by both the phase structure analysis and electrical properties. Despite a single 
O phase, the ceramics with $x=0.03$ still show the enhanced piezoelectric properties compared to other KNN-based ceramics with an AGS of 1-2 $\mu \mathrm{m}$, which may provide more options for inducing the desired electrical properties. More importantly, the AGS and the reduced degree of phase coexistence are successfully explained by considered the ion radius and different electronegativity values of ions. The reduced AGS is mainly attributed to the increasing content of $\mathrm{Ba}_{2}+$ and the reduced degree of phase coexistence is ascribed to the lower electronegativity of $\mathrm{Ba}_{2+}$ than $\mathrm{Bi}_{3+}$. The lower electronegativity of $\mathrm{Ba}_{2}+$ results in the increased ionic bond character and then increase the stabilization of the $\mathrm{O}$ phase, leading to an increase in Tо-т. Therefore, this work not only compares the controlling ability of $\mathrm{Ba}_{2}+$ and (Bi0.5 $\left.\mathrm{Ag}_{0.5}\right)_{2+}$ to $T_{\mathrm{O}-\mathrm{T}}$ but also significantly reveals which and how elements cause the reduced To-T, further helping understand the effects of additives on the phase structure.

\section{Acknowledgments}

The authors appreciate the support from the National Natural Science Foundation of China (Grants 51722208 and 51972215) and the Key Technologies Research and Development Program of Sichuan Province (Grant 2018JY0007). We thank Prof. Jürgen Rödel (Technische Universität Darmstadt) for measuring in situ temperature-dependent small signal $d 33$ values.

\section{Appendix A. Supplementary data}

Supplementary material related to this article can be found, in the online version.

\section{References}

[1] X. Lv, J. Zhu, D. Xiao, X.-X. Zhang, J. Wu, Emerging new phase boundary in potassium sodium- 
niobate based ceramics, Chem. Soc. Rev. 49(3) (2020) 671-707.

[2] J. Wu, D. Xiao, J. Zhu, Potassium-Sodium Niobate Lead-Free Piezoelectric Materials: Past, Present, and Future of Phase Boundaries, Chem. Rev. 115(7) (2015) 2559-2595.

[3] J. Rödel, K.G. Webber, R. Dittmer, W. Jo, M. Kimura, D. Damjanovic, Transferring lead-free piezoelectric ceramics into application, J. Eur. Ceram. Soc. 35(6) (2015) 1659-1681.

[4] J.F. Li, K. Wang, F.Y. Zhu, L.Q. Cheng, F.Z. Yao, (K,Na)NbO3-Based Lead-Free Piezoceramics: Fundamental Aspects, Processing Technologies, and Remaining Challenges, J. Am. Ceram. Soc. 96(12) (2013) 3677-3696.

[5] Y. Wang, C. Luo, S. Wang, C. Chen, G. Yuan, H. Luo, D. Viehland, Large Piezoelectricity in Ternary Lead-Free Single Crystals, Adv. Electron. Mater. (2019) 1900949.

[6] Y. Saito, H. Takao, T. Tani, T. Nonoyama, K. Takatori, T. Homma, T. Nagaya, M. Nakamura, Leadfree piezoceramics, Nature 432(7013) (2004) 84-87.

[7] H. Tao, H. Wu, Y. Liu, Y. Zhang, J. Wu, F. Li, X. Lyu, C. Zhao, D. Xiao, J. Zhu, Ultrahigh Performance in Lead-free Piezoceramics Utilizing a Relaxor Slush Polar State with Multiphase Coexistence, J. Am. Chem. Soc. 141(35) (2019) 13987-13994.

[8] Q. Liu, Y. Zhang, J. Gao, Z. Zhou, D. Yang, K.-Y. Lee, A. Studer, M. Hinterstein, K. Wang, X. Zhang, Practical High-Performance Lead-Free Piezoelectrics: Structural Flexibility Beyond Utilizing Multiphase Coexistence, Natl. Sci. Rev. (2019) https://doi.org/10.1093/nsr/nwz167.

[9] P. Li, J. Zhai, B. Shen, S. Zhang, X. Li, F. Zhu, X. Zhang, Ultrahigh Piezoelectric Properties in Textured (K,Na)NbO3-Based Lead-Free Ceramics, Adv. Mater. 30(8) (2018) 1705171.

[10] K. Xu, J. Li, X. Lv, J. Wu, X. Zhang, D. Xiao, J. Zhu, Superior Piezoelectric Properties in Potassium-Sodium Niobate Lead-Free Ceramics, Adv. Mater. 28(38) (2016) 8519-8523. 
[11] B. Wu, H. Wu, J. Wu, D. Xiao, J. Zhu, S.J. Pennycook, Giant piezoelectricity and high Curie temperature in nanostructured alkali niobate lead-free piezoceramics through phase coexistence, J. Am. Chem. Soc. 138(47) (2016) 15459-15464.

[12] X. Wang, J. Wu, D. Xiao, J. Zhu, X. Cheng, T. Zheng, B. Zhang, X. Lou, X. Wang, Giant piezoelectricity in potassium-sodium niobate lead-free ceramics, J. Am. Chem. Soc. 136(7) (2014) 2905-2910.

[13] Y. Zhang, J.-F. Li, Review of chemical modification on potassium sodium niobate lead-free piezoelectrics, J. Mater. Chem. C 7(15) (2019) 4284-4303.

[14] X. Wang, J. Wu, X. Lv, H. Tao, X. Cheng, T. Zheng, B. Zhang, D. Xiao, J. Zhu, Phase structure, piezoelectric properties, and stability of new $\mathrm{K}_{0.48} \mathrm{Na}_{0.52} \mathrm{NbO}_{3}-\mathrm{Bi}_{0.5} \mathrm{Ag}_{0.5} \mathrm{ZrO}_{3}$ lead-free ceramics, J. Mater. Sci: Mater. Electron. 25(7) (2014) 3219-3225.

[15] H. Tao, J. Wu, T. Zheng, X. Wang, X. Lou, New $(1-x) \mathrm{K}_{0.45} \mathrm{Na} 0.55 \mathrm{Nb} 0.96 \mathrm{Sb}_{0.04 \mathrm{O}}-x \mathrm{Bi} 0.5 \mathrm{Na} 0.5 \mathrm{HfO} 3$ lead-free ceramics: Phase boundary and their electrical properties, J. Appl. Phys. 118(4) (2015) 044102. [16] Z. Wang, D. Xiao, J. Wu, M. Xiao, F. Li, J. Zhu, New Lead-Free $(1-x)\left(\mathrm{K}_{0.5} \mathrm{Na}_{0.5}\right) \mathrm{NbO}_{3}-$ $x(\mathrm{Bi} 0.5 \mathrm{Na} 0.5) \mathrm{ZrO} 3$ Ceramics with High Piezoelectricity, J. Am. Ceram. Soc. 97(3) (2014) 688-690.

[17] Q. Liu, Y. Zhang, J. Gao, Z. Zhou, H. Wang, K. Wang, X. Zhang, L. Li, J.-F. Li, High-performance lead-free piezoelectrics with local structural heterogeneity, Energy Environ. Sci. 11(12) (2018) 3531 3539.

[18] K. Wang, F.Z. Yao, W. Jo, D. Gobeljic, V.V. Shvartsman, D.C. Lupascu, J.F. Li, J. Rödel, Temperature-Insensitive (K,Na)NbO3-Based Lead-Free Piezoactuator Ceramics, Adv. Funct. Mater. $23(33)(2013) 4079-4086$.

[19] Y. Zhang, L. Li, B. Shen, J. Zhai, Effect of orthorhombic-tetragonal phase transition on structure 
and piezoelectric properties of KNN-based lead-free ceramics, Dalton Trans. 44(17) (2015) 7797-7802. [20] C. Liu, D. Xiao, T. Huang, J. Wu, F. Li, B. Wu, J. Zhu, Composition induced rhombohedraltetragonal phase boundary in $\mathrm{BaZrO}_{3}$ modified $\left(\mathrm{K}_{0.445} \mathrm{Na} 0.50 \mathrm{Li} 0.055\right) \mathrm{NbO}_{3}$ lead-free ceramics, Mater. Lett. 120 (2014) 275-278.

[21] X. Wang, J. Wu, D. Xiao, X. Cheng, T. Zheng, X. Lou, B. Zhang, J. Zhu, New Potassium-Sodium Niobate Ceramics with a Giant d33, ACS Appl. Mater. Interfaces 6(9) (2014) 6177-6180.

[22] F. Rubio-Marcos, R. López-Juárez, R.E. Rojas-Hernandez, A. del Campo, N. Razo-Perez, J.F. Fernandez, Lead-free piezoceramics: revealing the role of the rhombohedral-tetragonal phase coexistence in enhancement of the piezoelectric properties, ACS Appl. Mater. Interfaces 7(41) (2015) 23080-23088.

[23] Y. Zhang, B. Liu, B. Shen, J. Zhai, Tolerance factor effect on the structure and properties of KNN based ceramics at orthorhombic-tetragonal phase boundary, J. Mater. Sci: Mater. Electron. 28(15) (2017) 11114-11118.

[24] H.-R. Wenk, L. Lutterotti, P. Kaercher, W. Kanitpanyacharoen, L. Miyagi, R. Vasin, Rietveld texture analysis from synchrotron diffraction images. II. Complex multiphase materials and diamond anvil cell experiments, Powder Diffr. 29(3) (2014) 220-232.

[25] L. Lutterotti, R. Vasin, H.-R. Wenk, Rietveld texture analysis from synchrotron diffraction images. I. Calibration and basic analysis, Powder Diffr. 29(1) (2014) 76-84.

[26] T. Leist, J. Chen, W. Jo, E. Aulbach, J. Suffner, J. Rödel, Temperature Dependence of the Piezoelectric Coefficient in $\mathrm{BiMeO}_{3}-\mathrm{PbTiO}_{3}\left(\mathrm{Me}=\mathrm{Fe}, \mathrm{Sc},\left(\mathrm{Mg}_{1 / 2} \mathrm{Ti}_{1 / 2}\right)\right)$ Ceramics, J. Am. Ceram. Soc. 95(2) (2012) 711-715.

[27] X. Sun, J. Zhang, X. Lv, Y. Liu, F. Li, J. Wu, Understanding Piezoelectricity of High-Performance 
Potassium Sodium Niobate Ceramics from Diffused Multi-phase Coexistence and Domain Feature, J. Mater. Chem. A 7(28) (2019) 16803-16811.

[28] J. Zhang, X. Sun, W. Su, W. Yao, C. Zhou, Superior piezoelectricity and rhombohedralorthorhombic-tetragonal phase coexistence of $(1-x)(\mathrm{K}, \mathrm{Na})(\mathrm{Nb}, \mathrm{Sb}) \mathrm{O}_{3}-x(\mathrm{Bi}, \mathrm{Na}) \mathrm{HfO}_{3}$ ceramics, Scripta Mater. 176 (2020) 108-111.

[29] C. Zhou, J. Zhang, W. Yao, D. Liu, W. Su, Highly temperature-stable piezoelectric properties of $0.96\left(\mathrm{~K}_{0.48} \mathrm{Na} 0.52\right)\left(\mathrm{Nb} 0.96 \mathrm{Sb}_{0.04}\right) \mathrm{O}_{3}-0.03 \mathrm{BaZrO}_{3}-0.01(\mathrm{Bi} 0.50 \mathrm{Na} 0.50) \mathrm{ZrO}_{3}$ ceramic in common usage temperature range, Scripta Mater. 162 (2019) 86-89.

[30] W. Yao, J. Zhang, C. Zhou, D. Liu, W. Su, Giant Piezoelectricity, Rhombohedral-OrthorhombicTetragonal Phase Coexistence and Domain Configurations of $(\mathrm{K}, \mathrm{Na})(\mathrm{Nb}, \mathrm{Sb}) \mathrm{O}_{3}-\mathrm{BiFeO}_{3}-(\mathrm{Bi}, \mathrm{Na}) \mathrm{ZrO}_{3}$ Ceramics, J. Eur. Ceram. Soc. 40(4) (2020) 1223-1231.

[31] M. Hinterstein, M. Hoelzel, J. Rouquette, J. Haines, J. Glaum, H. Kungl, M. Hoffman, Interplay of strain mechanisms in morphotropic piezoceramics, Acta Mater. 94 (2015) 319-327.

[32] W. Yang, P. Li, S. Wu, F. Li, B. Shen, J. Zhai, A Study on the Relationship Between Grain Size and Electrical Properties in $(\mathrm{K}, \mathrm{Na}) \mathrm{NbO}_{3}$-Based Lead-Free Piezoelectric Ceramics, Adv. Electron. Mater. (2019) 1900570.

[33] F. Li, S. Zhang, Z. Xu, L.Q. Chen, The Contributions of Polar Nanoregions to the Dielectric and Piezoelectric Responses in Domain-Engineered Relaxor-PbTiO3 Crystals, Adv. Funct. Mater. 27(18) (2017) 1700310.

[34] J. Hao, Z. Xu, R. Chu, W. Li, G. Li, Q. Yin, Relaxor behavior and dielectric properties of (La,Ta)modified (K0.5Na0.5)NbO3 lead-free ceramics, J. Alloys. Compd. 484(1-2) (2009) 233-238.

[35] F. Li, D. Lin, Z. Chen, Z. Cheng, J. Wang, C. Li, Z. Xu, Q. Huang, X. Liao, L.Q. Chen, Ultrahigh 
piezoelectricity in ferroelectric ceramics by design, Nat. Mater. 17(4) (2018) 349.

[36] K. Uchino, S. Nomura, L.E. Cross, R.E. Newnham, S.J. Jang, Electrostrictive effect in perovskites and its transducer applications, J. Mater. Sci. 16(3) (1981) 569-578.

[37] R. Wang, K. Wang, F. Yao, J.F. Li, F.H. Schader, K.G. Webber, W. Jo, J. Rödel, Temperature stability of lead-free niobate piezoceramics with engineered morphotropic phase boundary, J. Am. Ceram. Soc. 98(7) (2015) 2177-2182.

[38] M. Acosta, N. Novak, V. Rojas, S. Patel, R. Vaish, J. Koruza, G. Rossetti Jr, J. Rödel, BaTiO3based piezoelectrics: Fundamentals, current status, and perspectives, Appl. Phys. Rev. 4(4) (2017) 041305.

[39] J. Hao, W. Bai, W. Li, J. Zhai, Correlation Between the Microstructure and Electrical Properties in High-Performance (Ba0.85Ca0.15)(Zro.1Ti0.9)O3 Lead-Free Piezoelectric Ceramics, J. Am. Ceram. Soc. 95(6) (2012) 1998-2006.

[40] J. Yin, J. Wu, H. Wang, Composition dependence of electrical properties in $(1-x) \mathrm{KNbO}_{3}-x \mathrm{NaNbO}_{3}$ lead-free ceramics, J. Mater. Sci: Mater. Electron. 28(6) (2017) 4828-4838.

[41] F. Rubio-Marcos, J.F. Fernandez, D.A. Ochoa, J.E. García, R.E. Rojas-Hernandez, M. Castro, L. Ramajo, Understanding the piezoelectric properties in potassium-sodium niobate-based lead-free piezoceramics: interrelationship between intrinsic and extrinsic factors, J. Eur. Ceram. Soc. 37(11) (2017) 3501-3509.

[42] A. Esin, D. Alikin, A. Turygin, A. Abramov, J. Hreščak, J. Walker, T. Rojac, A. Bencan, B. Malic, A. Kholkin, Dielectric relaxation and charged domain walls in $(\mathrm{K}, \mathrm{Na}) \mathrm{NbO}_{3}$-based ferroelectric ceramics, J. Appl. Phys. 121(7) (2017) 074101.

[43] W. Wu, D. Xiao, J. Wu, J. Li, J. Zhu, B. Zhang, Microstructure and electrical properties of relaxor 
$(1-x)\left[\left(\mathrm{K}_{0.5} \mathrm{Na} 0.5\right) 0.95 \mathrm{Li} 0.05\right]\left(\mathrm{Nb} 0.95 \mathrm{Sb}_{0.05}\right) \mathrm{O}_{3}-x \mathrm{BaTiO}_{3}$ piezoelectric ceramics, Ceram. Int. 38(3) (2012) $2277-2282$.

[44] Z. Geng, K. Li, D. Shi, L. Zhang, X. Shi, Effect of Sr and Ba-doping in optical and electrical properties of KNN based transparent ceramics, J. Mater. Sci: Mater. Electron. 26(9) (2015) 6769-6775. [45] H. Khemakhem, A. Simon, R. Von Der Mühll, J. Ravez, Relaxor or classical ferroelectric behaviour in ceramics with composition Ba1-x $\mathrm{Na}_{x} \mathrm{Ti}_{1-x} \mathrm{Nb}_{x} \mathrm{O} 3$, J. Phys.: Condens. Matter 12(27) (2000) 5951.

[46] Y.-t. Guo, J. Xu, S.-y. Cao, Q. Chen, F. Gao, Microstructure and properties of $\mathrm{Bi}_{2} \mathrm{O}_{3}$ doped 0.8( $\left.\mathrm{K}_{0.52} \mathrm{Na} 0.48\right) \mathrm{NbO}_{3}-0.2 \mathrm{KSr}_{2} \mathrm{Nb}_{5} \mathrm{O}_{15}$ lead-free ceramics, IET Nanodielectrics 2(2) (2019) 55-60.

[47] Y.-X. Liu, H.-C. Thong, C. Zhao, Q. Liu, X. Xu, K. Wang, J.-F. Li, Influence of trace zirconia addition on the properties of (K,Na)NbO3 solid solutions, J. Mater. Chem. C 7 (2019) 6914-6923.

[48] X. Lv, J. Wu, J. Zhu, D. Xiao, X.x. Zhang, Temperature stability and electrical properties in Ladoped KNN-based ceramics, J. Am. Ceram. Soc. 101(9) (2018) 4084-4094.

[49] X. Lv, J. Wu, D. Xiao, Y. Yuan, H. Tao, J. Zhu, X. Wang, X. Lou, High unipolar strain in samariumdoped potassium-sodium niobate lead-free ceramics, RSC Adv. 5(49) (2015) 39295-39302.

[50] H. Tao, C. Zhao, R. Zhang, J. Wu, Rare earth element boosting temperature stability of (K,Na)NbO3-based ceramics, J. Alloys. Compd. 795 (2019) 401-407. 